\title{
Vibrational characterization of different benzene phases on flat and vicinal $\mathrm{Si}(100)$ surfaces
}

\author{
Borislav Naydenov ${ }^{\text {a) }}$ \\ School of Chemistry and the Centre for Research on Adaptive Nanostructures and Nanodevices (CRANN), \\ Trinity College, Dublin 2, Ireland \\ Wolf Widdra \\ Institute of Physics, Martin-Luther-Universität Halle-Wittenberg, Halle, Germany
}

(Received 30 April 2007; accepted 12 September 2007; published online 17 October 2007)

\begin{abstract}
Based on high-resolution electron energy loss spectroscopy and temperature-programmable desorption, benzene chemisorption on vicinal and nominally flat $\mathrm{Si}(100)$ surfaces has been studied for various adsorption, annealing, and site blocking treatments. Three different chemisorbed benzene $\left(\mathrm{C}_{6} \mathrm{H}_{6}\right.$ and $\left.\mathrm{C}_{6} \mathrm{D}_{6}\right)$ phases with distinct thermal desorption characteristics and different vibrational spectra have been separated and characterized on both substrates. All three phases are identified as 1,4-cyclohexadiene-like structures with butterfly geometry. Whereas the dominant phase is di- $\sigma$ bonded to the two $\mathrm{Si}$ atoms of a single $\mathrm{Si}-\mathrm{Si}$ dimer, the benzene orientation (double bond orientation) in the other phases is rotated. Di- $\sigma$ bonding to $\mathrm{Si}$ atoms of adjacent $\mathrm{Si}-\mathrm{Si}$ dimer for the latter cases is most likely. Coverage and temperature dependent conversions between the different phases have been addressed by vibrational spectroscopy. (c) 2007 American Institute of Physics. [DOI: 10.1063/1.2794341]
\end{abstract}

\section{INTRODUCTION}

Understanding the reactions of organic molecules with surfaces is one of the main topics in surface science and has various technological applications. ${ }^{1}$ The bonding of organic molecules to silicon and their property changes upon adsorption are still key issues in molecular electronics. ${ }^{1-3}$ Since the benzene molecule is the prototype molecule for a broad range of aromatic hydrocarbons, numerous studies have been focused on its adsorption on metal as well as on semiconductor surfaces. Among the various semiconductor surfaces, the $\mathrm{Si}(100)$ surface is by far the most important one due to its central role in microelectronics. Therefore many studies have been dedicated to aspects of benzene adsorption on $\mathrm{Si}(100)$ which concentrate on theoretical ${ }^{2,4-15}$ and experimental aspects, e.g., temperature-programmable desorption (TPD) spectroscopy and low-energy electron diffraction (LEED), ${ }^{6,16-18}$ scanning tunneling microscopy (STM), ${ }^{8,11,12,19-24}$ UV and x-ray photoelectron spectroscopies or near edge X-ray absorption fine structure spectroscopy (NAXAFS), 6,17,25-29 vibrational spectroscopies $9,16,20,25,30$ such as infrared absorption spectroscopy and high-resolution electron energy loss spectroscopy (HREELS), or other techniques. ${ }^{31}$

In the pioneering experimental work of Taguchi et al., ${ }^{16}$ it was found that benzene undergoes a nondissociative molecular chemisorption on the reactive $(2 \times 1)$-reconstructed $\mathrm{Si}(100)$ surface. Based on TPD, HREELS, LEED, and Auger electron spectroscopy results which showed an $s p^{3}$-hybridization of benzene carbon atoms which form $\sigma$-bonds with the Si substrate atoms, a preservation of the

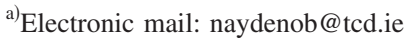

$\mathrm{Si}-\mathrm{Si}$ dimers was proposed. ${ }^{16}$ Additionally the vibrational spectrum contained a vibrational band located in the carbon double bond stretching region, suggesting the presence of $s p^{2}$-hybridized carbon atoms. A benzene saturation coverage of approximately 1/4 ML was determined. ${ }^{16}$ Two possible adsorbate geometries were alternatively proposed: a 1,4cyclohexadiene-like [standard butterfly (SB), see Fig. 1] and a 1,3-cyclohexadiene-like [tilted (T), see Fig. 1] structure both bonded to a single $\mathrm{Si}-\mathrm{Si}$ dimer. ${ }^{16}$ Theoretical investigations followed which, however, found different equilibrium configurations: Whereas the first theoretical work by $\mathrm{Craig}^{4}$ proposed a fourfold $\sigma$-bonded benzene species which is located on a single cleaved $\mathrm{Si}-\mathrm{Si}$ dimer based on a SLABMINDO method, Jeong et al. ${ }^{5}$ favored a pedestal benzene configuration (P in Fig. 1) with four $\sigma$-bonds to two silicon dimers, but with no double carbon bonds left in the molecule. In a combined angle-resolved UV photoelectron spectroscopy (ARUPS) and density-functional theory (DFT) cluster study, the first clear evidence for a $C_{2 v}$ symmetric
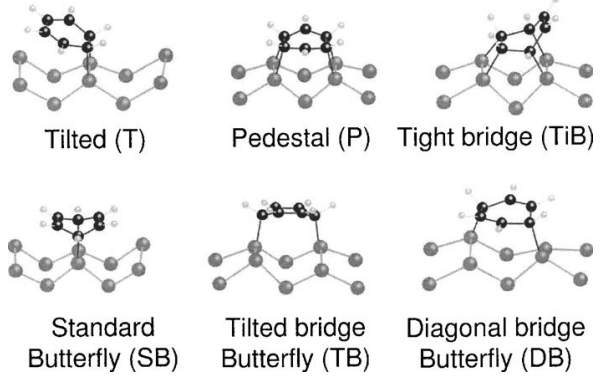

FIG. 1. Summary of the theoretically predicted stable configuration of benzene chemisorbed on a $\mathrm{Si}(100)-(2 \times 1)$ surface. Gray, black, and light gray atoms correspond to silicon, carbon, and hydrogen, respectively. The nomenclature follows Ref. 10 . 
1,4-cyclohexadiene-like butterfly structure was found for a saturated benzene layer. ${ }^{6}$ The carbon rehybridization and the presence of $\mathrm{C}=\mathrm{C}$ bonds which are oriented nearly parallel to the surface were confirmed by NEXAFS measurements. $^{25,26}$

The STM was used as a real-space imaging tool to address the benzene geometry but apart from the consensus concerning the adsorption on top of the $\mathrm{Si}-\mathrm{Si}$ dimer row, different stable configurations were proposed, namely, a standard butterfly (SB), ${ }^{19}$ a 1,3-cyclohexadiene-like (T), ${ }^{22}$ a pedestal $(\mathrm{P}),{ }^{21}$ and a tight bridge ${ }^{8,12,24}(\mathrm{TiB})$ structure. The different structural models are indicated in Fig. 1. The lowest energy was found for the TiB structure by recent $a b$ initio calculations. $^{10,12,14}$ On the other hand first-principles DFT cluster calculations by Birkenheuer et al. ${ }^{32}$ and Staufer et al. ${ }^{9}$ found excellent agreement between experimental and theoretical vibrational spectra only for the 1,4-cyclohexadienelike adsorption complex. Recent work using DFT with periodic boundary conditions was able to reproduce the HREEL spectra including the correct relative intensities. ${ }^{15}$ Although several DFT calculations with periodic boundary conditions found the tight bridge structure to be the lowest in energy, comparisons of calculated observables with available experimental data, especially for the symmetry-resolved electronic structure and the vibrational eigenmodes, gave good agreement for the standard butterfly structure only.

From experiment the standard butterfly structure is accepted as the dominant benzene phase for the saturated benzene layer on $\mathrm{Si}(100){ }^{6,9,13,15,28,31}$ A similar butterfly structure has been found also for benzene adsorption on $\mathrm{Ge}(100)$ and on a Ge monolayer on $\mathrm{Si}(100))^{33}$ This dominant benzene phase is related to the main feature in the thermal desorption spectrum of the saturated benzene monolayer on Si(100). ${ }^{6,16,17}$ However, it has been observed already early that the thermal desorption spectrum contains a second smaller peak suggesting the presence of a second minority adsorption site. ${ }^{6,16}$ It has been reported that preadsorption of 0.5 ML hydrogen suppresses the benzene high-temperature thermal desorption peak. ${ }^{6}$ This minor phase was attributed to adsorption on defect sites ${ }^{16}$ or at steps. ${ }^{6}$

A combination of theoretical calculations, STM, and FTIR was used to reveal a metastable standard butterfly structure for intermediate coverages of benzene adsorbed at $300 \mathrm{~K}$, which undergoes a time-dependent (hours) conversion to a more stable configuration. ${ }^{8,12,21,22}$ This has been taken as evidence for an energetically preferred benzene tight bridge structure (TiB in Fig. 1). The conversion into a second stronger bound benzene structure has been reported by another group but after annealing to $350 \mathrm{~K}^{25}$ A recent photoemission study reported indications for the presence of a minority benzene species on $\mathrm{Si}(100)$ already at $200 \mathrm{~K}^{29}$ Thus the strongly bound benzene phases on $\mathrm{Si}(100)$ are still under debate as well as aspects of the benzene structure at initial and intermediate coverages. However, some of the reported experiments have been performed on vicinal $\mathrm{Si}(100)$ to obtain single-domain surfaces other on nominally flat $\mathrm{Si}(100)$. One might argue that this difference could be a reason for the discrepancies discussed.

Therefore the goal of the present study is to separate distinctly different benzene $\left(\mathrm{C}_{6} \mathrm{H}_{6}\right.$ and $\left.\mathrm{C}_{6} \mathrm{D}_{6}\right)$ phases on vicinal and nominally flat $\mathrm{Si}(100)-(2 \times 1)$ surfaces and to characterize them by HREELS and TPD. HREELS is most likely the best suited method to address the open questions regarding the nature of different adsorbed species due to the detailed information on intermolecular bonding and strain as well as on molecule-substrate interaction. Based on highly resolved vibrational data, we will discuss three different phases which will be all identified as 1,4-cyclohexadienelike benzene structures. All phases are di- $\sigma$ bonded to the $\mathrm{Si}(100)$ substrate and exhibit a butterfly geometry. However, the bonding occurs to different Si surface atoms which implies different strains in the molecule and leads to different butterfly orientations.

\section{EXPERIMENT}

The experiments were performed in a two-level UHV system with base pressure below $5 \times 10^{-11}$ mbar which has been described in detail elsewhere. ${ }^{34}$ The upper (preparation) chamber houses standard four-grid LEED optics, quadrupole mass spectrometer equipped with a Feulner cap, ${ }^{35} \mathrm{Ar}^{+}$-ion sputter gun, and different dosing facilities. In the lower chamber a HREEL spectrometer (Delta 05, VSI) is available with an overall experimental resolution better than $8 \mathrm{~cm}^{-1} \cdot 36$ For the bare and hydrogenated semiconductor $\mathrm{Si}(100)$ surface, best resolutions of 17 and $11.3 \mathrm{~cm}^{-1}$, respectively, have been achieved in this work with intensities of the specular reflected beam of $2 \times 10^{5}$ and $1.2 \times 10^{5} \mathrm{~s}^{-1}$. The electron scattering plane was perpendicular to the surface and the specular angle between the incoming and outgoing electron beams was approximately $120^{\circ}$. The vicinal silicon crystal was oriented such that the electron scattering plane was along the [011] direction which is parallel to the $\mathrm{Si}-\mathrm{Si}$ dimers. On the nominally flat sample, the electron scattering plane projection on the surface formed a $45^{\circ}$ azimuthal angle relative to the silicon dimers on both orthogonal surface domains. The $n$-type, phosphorus-doped Si samples were either highly (100) oriented or oriented off axis with a miscut angle of $5^{\circ}$ toward the $[011]$ direction. The crystals were ex situ oriented by $\mathrm{x}$-ray diffraction. The sample mounting using a silver bonding technique which allowed excellent temperature control and cooling has been described elsewhere. ${ }^{37}$ Using a liquid helium cryostat, samples can be cooled to $30 \mathrm{~K}$ and resistively heated to $1300 \mathrm{~K}$. After introduction into the UHV chamber, the samples were outgassed at $700 \mathrm{~K}$ for 8-10 h. Several cycles of argon-ion sputtering at RT and $800 \mathrm{~K}$ were performed followed by annealing up to $1200 \mathrm{~K}$ until sharp $(2 \times 1)$ LEED patterns and no contaminationrelated features in the HREEL spectrum were obtained. Atomic hydrogen was adsorbed at 650 and $400 \mathrm{~K}$ at which temperatures only monohydridge or mono-plus dihydride are formed on the $\mathrm{Si}(100)$ surface, respectively. ${ }^{38,39}$ The atomic hydrogen was obtained by $\mathrm{H}_{2}$ dissociation in a tungsten capillary inlet which is kept at $1860{ }^{\circ} \mathrm{C}$. ${ }^{40}$ 

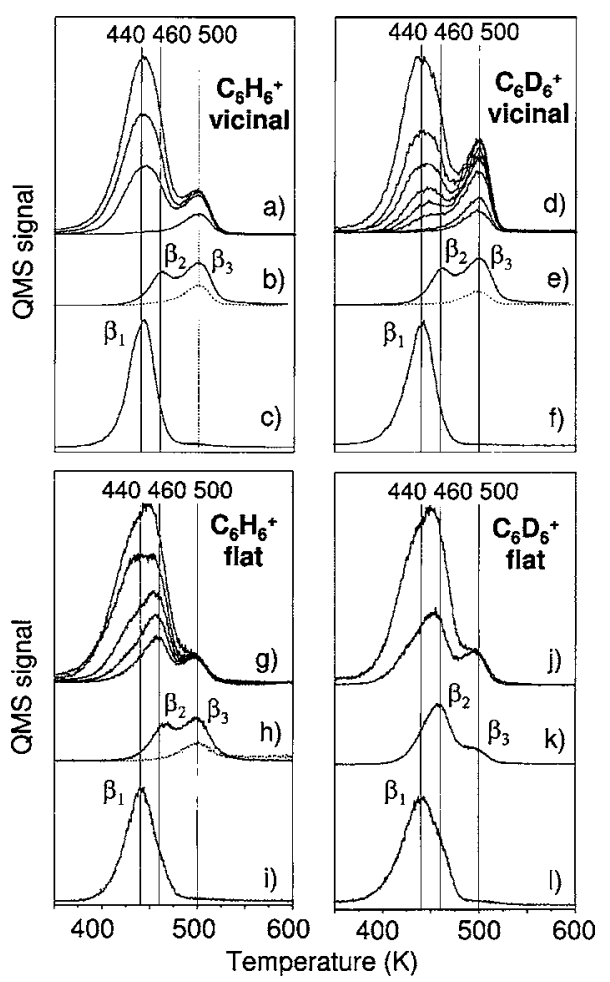

FIG. 2. TPD spectra of benzene adsorbed on $\mathrm{Si}(100)-(2 \times 1)$. [(a)-(c)] Hydrogenated and [(d)-(f)] deuterated benzene adsorbed at $100 \mathrm{~K}$ on a vicinal $\mathrm{Si}(100)$ surface, measured with $5 \mathrm{~K} / \mathrm{s}$. [(g)-(i)] Hydrogenated and [(j)(1) ] deuterated benzene adsorbed at $90 \mathrm{~K}$ on a vicinal $\mathrm{Si}(100)$ surface, measured with $2 \mathrm{~K} / \mathrm{s}$. Spectra (a), (d), (g), and (j) are taken after successively increased benzene doses. Spectra (b), (e), and (h) are for saturation coverages $\theta=1$ (solid line) and $\theta=0.2$ (dotted line) upon annealing to $440 \mathrm{~K}$. (k) Spectrum of $\theta_{\mathrm{C}_{6} \mathrm{D}_{6}}>1$ preannealed to $430 \mathrm{~K}$. [(c) and (f)] Present results of benzene-saturated surface after its passivation with a half monolayer of hydrogen at $650 \mathrm{~K}$. [(i) and (1)] Present results of benzene-saturated surface after its passivation with $\theta_{\mathrm{H}}=0.25$ at $650 \mathrm{~K}$. The temperatures of the $\beta_{1}, \beta_{2}$, and $\beta_{3}$ desorption peaks are indicated in the upper parts.

\section{RESULTS}

\section{A. Thermal desorption}

In Fig. 2 TPD spectra of hydrogenated and deuterated benzene adsorbed at $100 \mathrm{~K}$ on a vicinal and at $90 \mathrm{~K}$ on nominally flat $\mathrm{Si}(100)$ surface are shown. The physisorbed benzene desorbs below $150 \mathrm{~K}$; details can be found in Refs. 6 and 16. Because in this work we focus on the chemisorption phases, the temperature range where these phases appear in the desorption spectrum is included in Fig. 2 only. In the spectra for small exposures of $\mathrm{C}_{6} \mathrm{H}_{6}$ and $\mathrm{C}_{6} \mathrm{D}_{6}$ as shown in Figs. 2(a) and 2(d), respectively, a single desorption peak $\left(\beta_{3}\right)$ centered at $500 \mathrm{~K}$ is resolved. With increasing benzene exposure, a broad structure starts to grow which dominates at lower desorption temperatures before saturation of the $\beta_{3}$ peak. The main peak saturates centered at $440 \mathrm{~K}$. On flat $\mathrm{Si}(100)$ surfaces it possesses a fine structure, as shown in Figs. 2(g) and 2(j). Benzene adsorption after Si(100) surface passivation at $650 \mathrm{~K}$ with $0.5 \mathrm{ML}$ hydrogen on a vicinal and with $0.25 \mathrm{ML}$ hydrogen on a flat surface leads to desorption spectra [see Figs. 2(c), 2(f), 2(g), and 2(1)] with a sharp single peak $\left(\beta_{1}\right)$ centered at $440 \mathrm{~K}$. The desorption spectra of saturated benzene layers which have been preannealed to $440 \mathrm{~K}$ for $5 \mathrm{~s}$ are shown as solid lines in Figs. 2(b), 2(e),

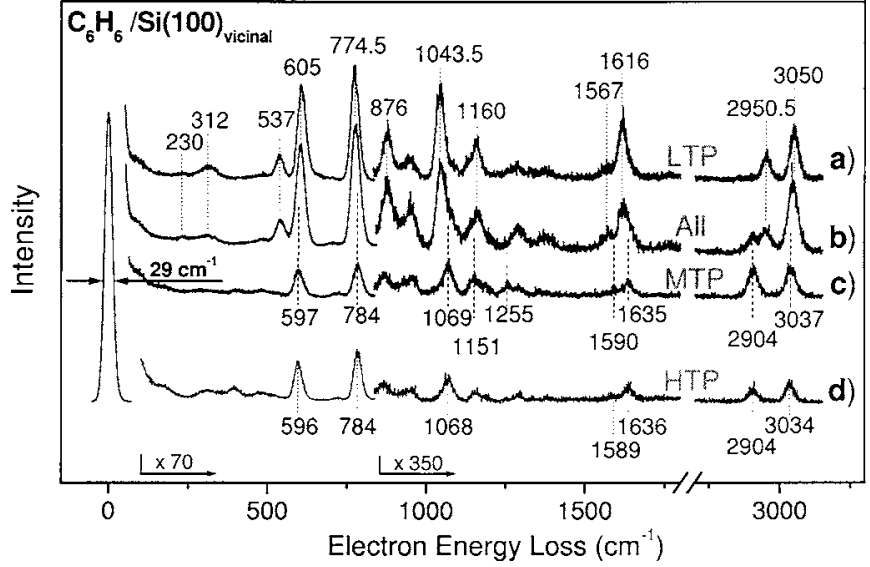

FIG. 3. HREEL spectra of $\mathrm{C}_{6} \mathrm{H}_{6}$ adsorbed on a vicinal $\mathrm{Si}(100)$ surface $(4 \mathrm{eV}$ electron energy, specular scattering geometry, $100 \mathrm{~K}$ substrate temperature): (a) Benzene saturation at $100 \mathrm{~K}$ after surface passivation with $0.4 \mathrm{ML}$ atomic hydrogen at $650 \mathrm{~K}$, subsequently annealed up to $300 \mathrm{~K}$; (b) saturation at $100 \mathrm{~K}$ and annealing up to $300 \mathrm{~K}$; [(c) and (d)] benzene coverage $\theta=0.2$ annealed up to 430 and $450 \mathrm{~K}$, respectively. The amplification factors with respect to the elastic peak are shown at the bottom.

2(h), and 2(k). All four desorption spectra contain a well resolved double structure. The high-temperature peak corresponds to the $\beta_{3}$ peak for the saturated layer while the second peak centered at $460 \mathrm{~K}$ (denoted as $\beta_{2}$ in the following) has no direct analog in the spectra on the vicinal sample in Figs. 2(a) and 2(d). In contrast, on the flat surface the $\beta_{2}$ peak has an analog in the fine structure of the spectra for saturation coverage seen in Figs. 2(g) and 2(j).

As is demonstrated in Fig. 2, it is possible to prepare three well defined adsorbate phases on the $\mathrm{Si}(100)$ surface, which probably coexist in the saturated benzene layer. For clarity in the following we base our notations on these TPD results. Namely, we denote as low-temperature phase (LTP), middle-temperature phase (MTP), and high-temperature phase (HTP) the phases which produce the TPD spectral structures $\beta_{1}, \beta_{2}+\beta_{3}$, and $\beta_{3}$, respectively. The three phases were prepared by preadsorption of atomic hydrogen at $650 \mathrm{~K}$ [Figs. 2(c), 2(f), 2(i), and 2(1)], by a brief (5 s) annealing of a saturated layer to $440 \mathrm{~K}$ [solid lines in Figs. 2(b), 2(e), $2(\mathrm{~h})$, and $2(\mathrm{k})]$, and by annealing up to $440 \mathrm{~K}$ (for $60 \mathrm{~s}$ ) of $\theta_{\mathrm{C}_{6} \mathrm{H}_{6}}=0.2 \mathrm{ML}$ benzene [dotted line in Figs. 2(b), 2(e), and $2(\mathrm{~h})]$, respectively. $\theta_{\mathrm{C}_{6} \mathrm{H}_{6}}=1 \mathrm{ML}$ corresponds to the saturation coverage of chemisorbed benzene on $\mathrm{Si}(100)$.

\section{B. Vibrational characterization by HREELS}

HREEL spectra for the saturated benzene $\left(\mathrm{C}_{6} \mathrm{H}_{6}\right)$ layer and for the three separate phases on a vicinal $\mathrm{Si}(100)$ surface are presented in Figs. 3(b), 3(a), 3(c), and 3(d), respectively. The three phases have been prepared as described in Sec. III A. The vibrational spectra of the different benzene phases reveal a great similarity in the number of loss features and their frequencies and intensities. The vibrational frequencies of the MTP and HTP in Figs. 3(c) and 3(d) are essentially the same within $\pm 5 \mathrm{~cm}^{-1}$ and only the peak at $1255 \mathrm{~cm}^{-1}$ vanishes in the HTP spectrum. A comparison of both MTP and HTP spectra with the LTP spectrum in Fig. 3(a) shows in general very similar loss intensity ratios but frequency shifts 


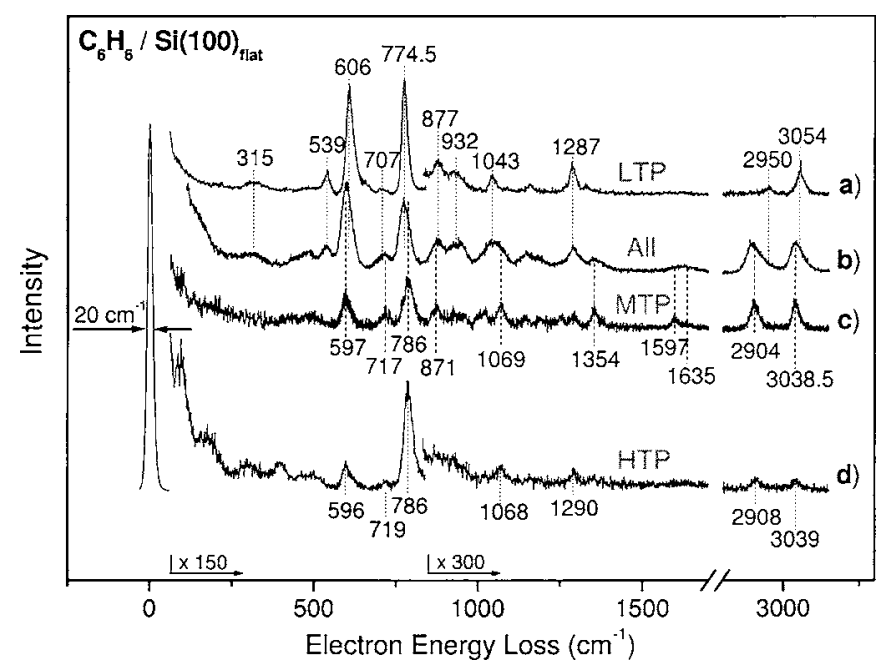

FIG. 4. HREEL spectra of $\mathrm{C}_{6} \mathrm{H}_{6}$ adsorbed on a nominally flat $\mathrm{Si}(100)$ surface $(4 \mathrm{eV}$ electron energy, $90 \mathrm{~K}$ ): (a) Benzene coverage $\theta>1$ adsorbed at $90 \mathrm{~K}$ after surface passivation with $0.25 \mathrm{ML}$ atomic hydrogen at $650 \mathrm{~K}$, subsequently annealed up to $300 \mathrm{~K}$; (b) adsorption $\theta>1$ at $90 \mathrm{~K}$ and annealed up to $300 \mathrm{~K}$; [(c) and (d)] benzene coverage $\theta=0.2$ annealed up to 440 and $470 \mathrm{~K}$, respectively.

up to $50 \mathrm{~cm}^{-1}$ for some vibrational modes. In the spectrum of a benzene-saturated surface as displayed in Fig. 3(b), all losses are broader while the instrumental resolution is the same. It indicates that this spectrum is a superposition of different phases. This is obvious in the region around $3000 \mathrm{~cm}^{-1}$ where three peaks are present corresponding to the two peaks in the LTP and the MTP (HTP) spectra. Additionally the numerical summation of the LTP and MTP spectra (not shown here) reproduces in detail curve (b) in Fig. 3. A coexistence of the three phases in the saturated benzene layer can be deduced in accordance with the thermal desorption results shown in Fig. 2.

Similar as in Fig. 3 for the vicinal surface, HREEL spectra of $\mathrm{C}_{6} \mathrm{H}_{6}$ saturation and of the three separate phases on the nominally flat $\mathrm{Si}(100)$ surface are shown in Figs. 4(b), 4(a), 4(c), and 4(d). The benzene frequencies of all phases agree within a few $\mathrm{cm}^{-1}$ with the corresponding values on the vicinal surface. However, some differences with respect to the loss intensities are found which are expected due to the different scattering geometries with altered excitation cross sections. In comparison to the spectrum of the MTP in Fig. 4(c), there is a strong intensity reduction of the modes above $500 \mathrm{~cm}^{-1}$ for the HTP visible in Fig. 4(d). This can be explained by the lower adsorbate coverage of the HTP which in this case is less than half of the MTP. Thus the modes with small intensity in the spectrum of the MTP are not resolvable in the spectrum of the HTP. The observation that all strong losses of the MTP are preserved in the HTP spectrum with less than $4 \mathrm{~cm}^{-1}$ shifts (except for a vanishing loss at $1354 \mathrm{~cm}^{-1}$ ) suggests almost identical benzene structures in the MTP and the HTP. Comparison of the spectra of MTP and LTP in Figs. 4(c) and 4(a) yields frequency shifts up to $45 \mathrm{~cm}^{-1}$ and also reversed intensity ratios. The spectrum for benzene saturation is shown in Fig. 4(b) and can be understood as superposition of the spectra of the LTP and MTP
[Figs. 4(a) and 4(c)] as has been concluded similarly for adsorption on the vicinal $\mathrm{Si}(100)$ surface.

For the vibrational mode assignment, we start from the assignment made by Staufer et al. ${ }^{9}$ for the butterfly adsorbate structure found for a saturated benzene layer on a vicinal $\mathrm{Si}(100)$ surface. We will follow the notations introduced in Ref. 9, namely. $\mathrm{Si}_{d}$ for silicon dimer atoms involved in bonding with benzene carbon atoms, $\mathrm{C}_{d}$ for the $s p^{3}$-hybridized carbon atoms bonded to the substrate, $\mathrm{C}$ for $s p^{2}$-hybridized carbon atoms not bonded to silicon, and $\mathrm{H}$ and $\mathrm{H}_{d}$ for hydrogen attached to $s p^{2}$ and $s p^{3}$ carbon, respectively.

The high-frequency spectral region above $2900 \mathrm{~cm}^{-1}$ in the MTP spectra in Figs. 3 and 4 is characterized by two peaks arising from the $\mathrm{C}-\mathrm{H}$ and $\mathrm{C}_{d}-\mathrm{H}_{d}$ stretching modes. The MTP bands are redshifted compared to the corresponding LTP modes; however, the bandwidths are preserved, suggesting a force constant softening rather than changes in the mode character. The $\mathrm{C}_{d}-\mathrm{H}_{d}$ stretching at $2904 \mathrm{~cm}^{-1}$ is shifted to $2950 \mathrm{~cm}^{-1}$. This shift is more than twice the shift of the $\mathrm{C}-\mathrm{H}$ stretching mode at about 3040 and $3054 \mathrm{~cm}^{-1}$, manifesting that the $\mathrm{C}_{d}$ atoms are in the center of the structural changes between the different phases. As the carbonhydrogen bonds are softened, the carbon-carbon bonds should become stiffer and indeed the symmetric and asymmetric $\mathrm{C}=\mathrm{C}$ stretching modes around $1600 \mathrm{~cm}^{-1}$ are blueshifted with $20 \mathrm{~cm}^{-1}$ best visible on the vicinal surface. For the in-plane $\left(1100-1350 \mathrm{~cm}^{-1}\right)$ and out-of-plane $\left(650-1050 \mathrm{~cm}^{-1}\right)$ carbon-hydrogen bending modes, the shifts cannot be simply deduced from the $\mathrm{C}-\mathrm{H}$ and $\mathrm{C}-\mathrm{C}$ bond strength changes because both forces with varying contributions are involved in these vibrations. This leads to various positive and negative shifts of the $\mathrm{C}-\mathrm{H}$ and $\mathrm{C}_{d}-\mathrm{H}_{d}$ bending modes. The fully symmetric benzene ring breathing frequencies at 605 and $876 \mathrm{~cm}^{-1}$ for the LTP are reduced by 6-9 $\mathrm{cm}^{-1}$ in the MTP, suggesting a small effect of the shortened $\mathrm{C}=\mathrm{C}$ bond. The most dramatic changes occur for the mode related to the $\mathrm{Si}_{d}-\mathrm{C}_{d}$ stretching plus butterfly motion of the benzene molecule at about $538 \mathrm{~cm}^{-1}$ for the LTP. This mode vanishes in the spectra of MTP and HTP. The mode either shifts up in frequency and is not resolvable from the neighboring more intensive peak, or it shifts down and in the changed symmetry couples with a substrate phonon band. The former is less probable because this would require a shift of $60 \mathrm{~cm}^{-1}$, and also no broadening of the adjacent peak is observed.

To corroborate the mode assignment, we examined the isotope effect on the vibrational characteristics by adsorbing deuterated benzene on flat and vicinal $\mathrm{Si}(100)$ surfaces. In Figs. 5(a), 5(c), and 5(d) HREEL spectra of the three $\mathrm{C}_{6} \mathrm{D}_{6}$ phases on the vicinal $\mathrm{Si}(100)$ surface are plotted together with the spectrum for saturation coverage in Fig. 5(b). As in the nondeuterated case, the similarity of the peak positions and ratios is preserved for the three phases within $30 \mathrm{~cm}^{-1}$ shifts. Again the spectrum of the saturation layer is a superposition of the LTP and MTP spectra, suggesting coexistence of the different phases. In the carbon-deuterium stretching region, three bands are resolved which agree with the theoretical predictions. ${ }^{9}$ These three modes for the MTP (and the HTP) are redshifted compared to the LTP, manifesting a 


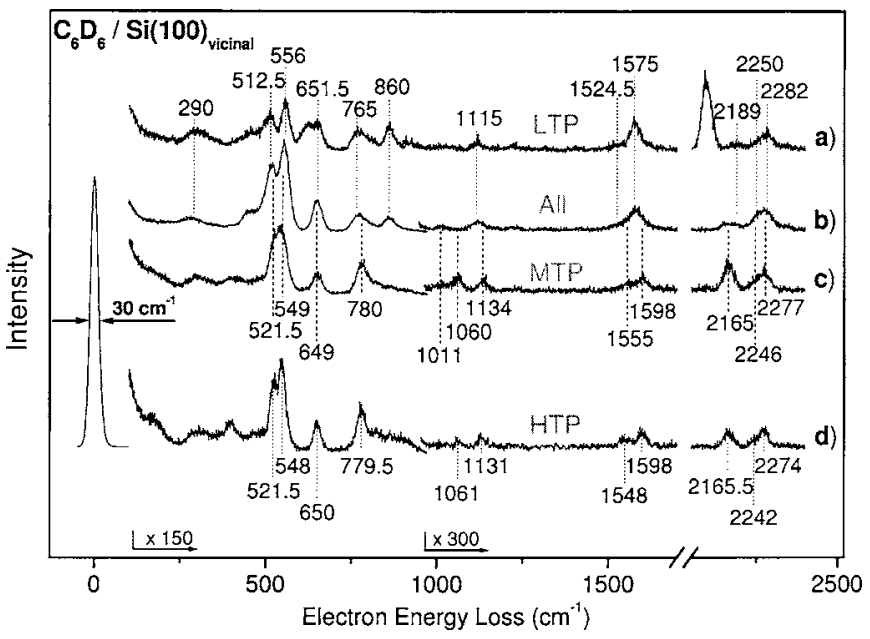

FIG. 5. HREEL spectra of $\mathrm{C}_{6} \mathrm{D}_{6}$ adsorbed on a vicinal $\mathrm{Si}(100)$ surface (4 eV electron energy, $100 \mathrm{~K}$ ): (a) Benzene saturation at $100 \mathrm{~K}$ after surface passivation with $0.4 \mathrm{ML}$ atomic hydrogen at $650 \mathrm{~K}$, subsequently annealed up to $300 \mathrm{~K}$; (b) saturation at $100 \mathrm{~K}$ and annealing up to $300 \mathrm{~K}$; [(c) and (d)] benzene coverage $\theta=0.2$ annealed up to 430 and $450 \mathrm{~K}$, respectively. The two losses at 2100 and $621 \mathrm{~cm}^{-1}$ not marked in (a) belong to the monohydride vibrations.

bond softening. The $\mathrm{C}=\mathrm{C}$ stretching doublet around $1580 \mathrm{~cm}^{-1}$ is prominent, particularly in the MTP and HTP cases, in which they undergo blueshifts of about $23 \mathrm{~cm}^{-1}$ with respect to the LTP. All carbon-deuterium bending modes are isotope shifted to lower frequencies where they couple with each other and with the ring deformation modes. Different couplings due to the isotope shift are found for the vibration at $860 \mathrm{~cm}^{-1}$ prominent in the LTP compared to the MTP and HTP. In this region three vibrational modes are predicted in the calculations of Staufer et al. ${ }^{9}$ two of them being totally symmetric, and as a consequence a unique assignment is impossible here.

The HREEL spectra of the deuterated benzene LTP, MTP, and saturation coverage on a flat $\mathrm{Si}(100)$ surface are shown in Figs. 6(a), 6(c), and 6(b), respectively. The abovementioned observations on a vicinal surface hold also for the

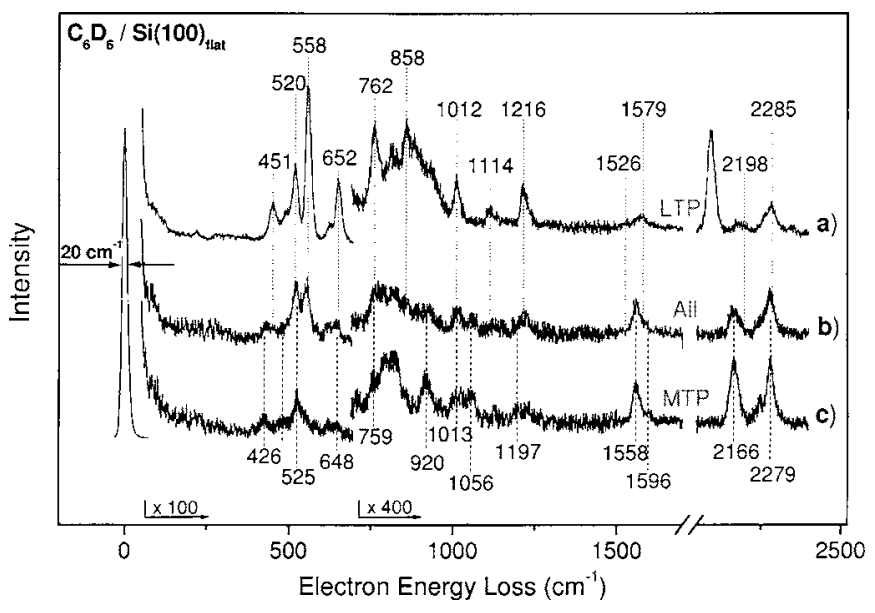

FIG. 6. HREEL spectra of $\mathrm{C}_{6} \mathrm{D}_{6}$ adsorbed on a nominally flat $\mathrm{Si}(100)$ surface ( $4 \mathrm{eV}$ electron energy, $90 \mathrm{~K}$ ): (a) Benzene coverage $\theta>1$ adsorbed at $90 \mathrm{~K}$ after surface passivation with $0.25 \mathrm{ML}$ atomic hydrogen at $650 \mathrm{~K}$, subsequently annealed up to $300 \mathrm{~K}$; (b) adsorption $\theta>1$ at $90 \mathrm{~K}$ and annealed up to $300 \mathrm{~K}$; (c) benzene coverage $\theta=0.2$ annealed up to $430 \mathrm{~K}$.

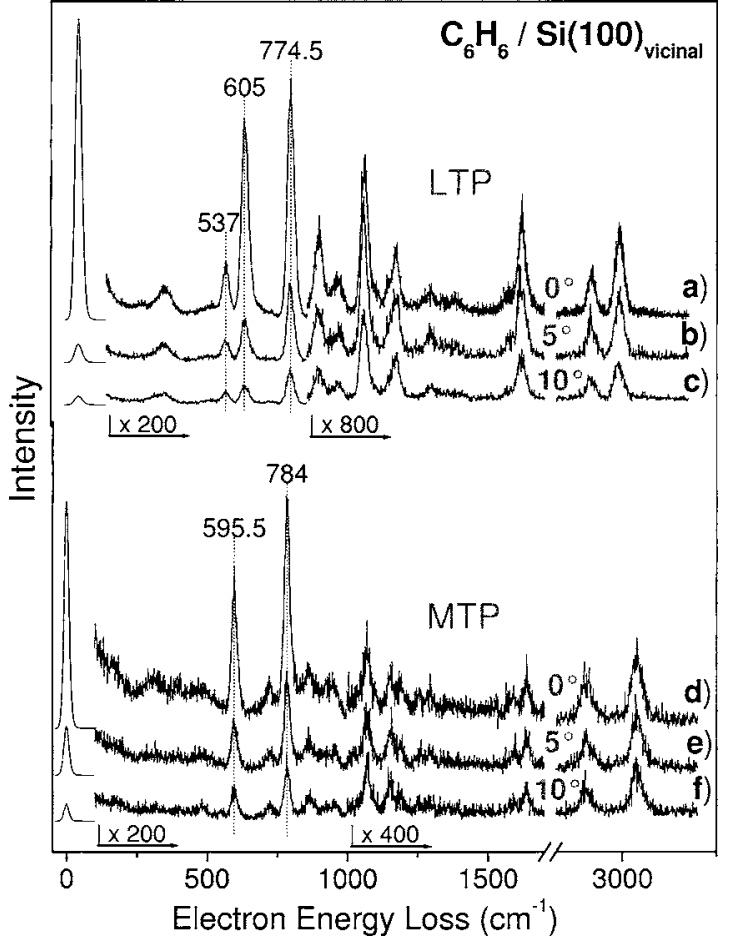

FIG. 7. Off-specular HREEL spectra of $\mathrm{C}_{6} \mathrm{H}_{6}$ adsorbed on a vicinal $\mathrm{Si}(100)$ surface $(4 \mathrm{eV}$ electron energy, $100 \mathrm{~K})$ : Spectra of the benzene lowtemperature phase (LTP) with increasing off-specular angle from (a) $0^{\circ}$, to (b) $5^{\circ}$, to (c) $10^{\circ}$. Spectra of the medium-temperature phase (MTP) are shown for $0^{\circ}, 5^{\circ}$, and $10^{\circ}$ off-specular angles in (d), (e), and (f), respectively. Only modes with significant dynamical dipole moment are labeled with their frequencies.

spectra on the flat surface shown in Fig. 6. The vibrational frequencies are well reproduced while the loss intensities are significantly altered due to the different scattering geometries. The latter is best visible for the $\mathrm{C}=\mathrm{C}$ stretching doublet around $1600 \mathrm{~cm}^{-1}$ where in contrast to the vicinal surface the lower frequency mode becomes dominant in the MTP spectrum in Fig. 6(c).

In Fig. 7 HREEL spectra recorded in $0^{\circ}, 5^{\circ}$ and $10^{\circ}$ off-specular geometries are presented for the benzene LTP and MTP on the vicinal $\mathrm{Si}(100)$ surface. The analysis of the intensity variations with off-specular angle for all loss features and the elastic peak shows that only the vibrations at 537,605 , and $774.5 \mathrm{~cm}^{-1}$ for the LTP and the modes at 595.5 and $784 \mathrm{~cm}^{-1}$ for the MTP have significant dipole-active components. All other losses are excited dominantly by the impact scattering mechanism. Similar results are found for benzene on flat $\mathrm{Si}(100)$ surfaces (not shown here). Apart from dipole selection rules which define the forbidden modes in off-specular scattering geometry and which can be applied to only a few modes here, impact selection rule can be applied in cases of high-symmetry scattering geometries. Our particular geometry on the vicinal and single-domain $\mathrm{Si}(100)$ surface with the scattering plane aligned parallel to the $\mathrm{Si}-\mathrm{Si}$ dimer bond is well suited for such an analysis. For impact scattering within a surface mirror plane, vibrations with odd symmetry with respect to the scattering plane are forbidden. Consequently, modes belonging to the $A_{2}$ and $B_{2}$ irreducible representations in the $C_{2 v}$ point group of the "butterfly" ad- 


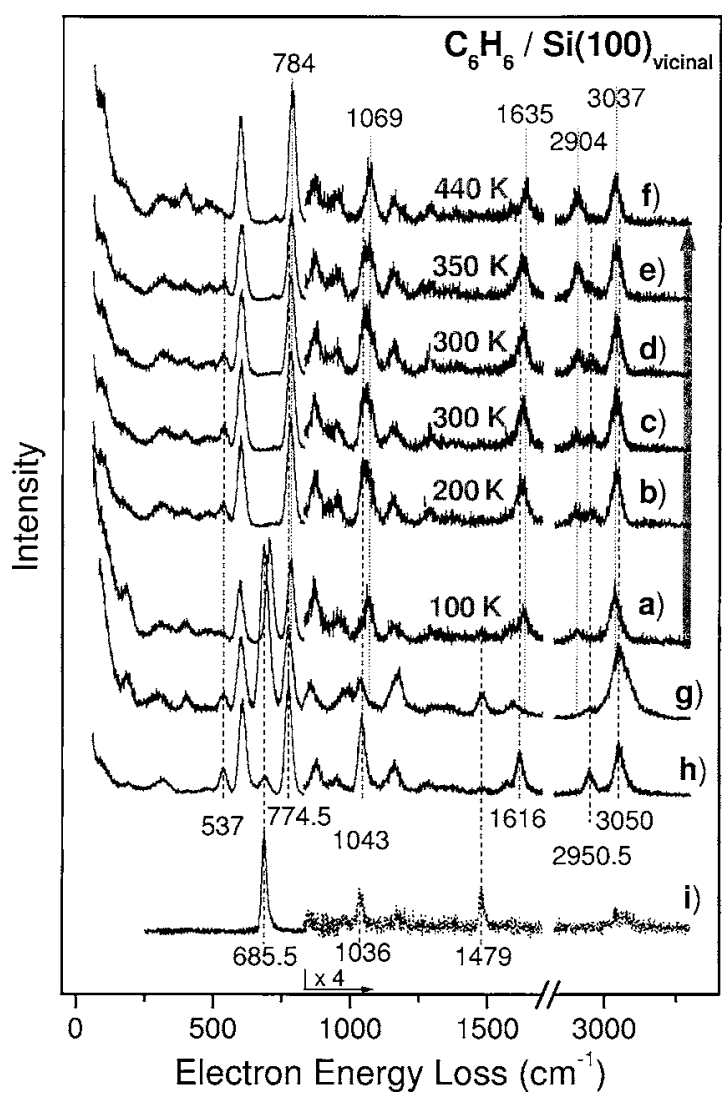

FIG. 8. HREEL spectra of $\mathrm{C}_{6} \mathrm{H}_{6}$ adsorbed on a vicinal $\mathrm{Si}(100)$ surface as a function of annealing temperature $(4 \mathrm{eV}$ electron energy, measured at $100 \mathrm{~K}$ ): Low coverage spectra $\theta=0.2$ taken (a) without annealing and after successive annealing ( $5 \mathrm{~s}$ hold time) up to (b) $200 \mathrm{~K}$, (c) $300 \mathrm{~K}$, (d) $300 \mathrm{~K}$ with $600 \mathrm{~s}$ hold time, (e) $350 \mathrm{~K}$, and (f) $440 \mathrm{~K}$. Spectrum for saturation coverage at $100 \mathrm{~K}$ is shown in $(\mathrm{g})$. (h) Saturation at $100 \mathrm{~K}$ after passivation with $0.40 \mathrm{ML}$ atomic hydrogen at $650 \mathrm{~K}$. (i) Difference of the spectra measured on $\mathrm{H} / \mathrm{Si}(100)-(3 \times 1)$ with and without physisorbed benzene.

sorbate complex are impact forbidden. This selection rule will be applied for the mode assignment of the LTP in the discussion below (see Sec. IV).

On a $\mathrm{Si}(100)$ surface, STM observations at low benzene coverages for adsorption at $300 \mathrm{~K}$ have been interpreted by Lopinski et $a l^{20,21}$ as a metastable standard butterfly structure (SB in Fig. 1) which converts with a time constant of hours to a more stable tight bridge configuration (TiB in Fig. 1). Converted into our notations, this conclusion claims that the LTP is a metastable adsorption product at $300 \mathrm{~K}$ which converts with time to the more stable MTP (HTP). To examine this proposal we have investigated the benzene structure at low coverage $\left(\theta_{\mathrm{C}_{6} \mathrm{H}_{6}}=0.2-0.3 \mathrm{ML}\right)$ adsorbed at $90-100 \mathrm{~K}$ as a function of annealing temperature. The resulting HREEL spectra for $\mathrm{C}_{6} \mathrm{H}_{6}$ on a vicinal surface are plotted in Fig. 8. For comparison the spectrum of physisorbed benzene with vibrations at $685.5,1036,1479$, and $3060 \mathrm{~cm}^{-1}$ is presented in Fig. 8(i). These energy losses correspond to the symmetric out-of-plane $\mathrm{C}-\mathrm{H}$ bending, the in-plane $\mathrm{C}-\mathrm{H}$ bending, the $\mathrm{C}-\mathrm{C}$ stretching, and the $\mathrm{C}-\mathrm{H}$ stretching modes, respectively. ${ }^{4}$ The spectrum was obtained after benzene adsorption at $100 \mathrm{~K}$ on the ordered $\mathrm{Si}(100)-4 H-(3 \times 1)$ where all silicon dangling bonds are saturated by hydrogen. The low coverage spectrum direct after benzene adsorption as shown in Fig. 8(a) reveals chemisorbed benzene in the MTP with its characteristic losses at 784, 1069, and $2904 \mathrm{~cm}^{-1}$, together with a physisorbed phase with a characteristic loss at $705 \mathrm{~cm}^{-1}$. The out-of-plane $\mathrm{C}-\mathrm{H}$ bending mode of the latter as seen in Fig. 8(a) is blueshifted by about $20 \mathrm{~cm}^{-1}$ relative to benzene physisorbed on a $\mathrm{H}$-passivated surface, Fig. 8(i). Annealing to $200 \mathrm{~K}$ is sufficient to convert the physisorbed benzene to the chemisorbed LTP as is indicated in Fig. 8(b) by the appearance of the characteristic losses at 537, 1043, and $2950.5 \mathrm{~cm}^{-1}$ together with the disappearance of the $705 \mathrm{~cm}^{-1}$ loss. This conversion occurs while the MTP remains unchanged as is seen by the preserved peak at $2904 \mathrm{~cm}^{-1}$. Annealing to $300 \mathrm{~K}$ for a few seconds and for $600 \mathrm{~s}$ as shown in Figs. 8(c) and 8(d) does not alter the vibrational spectrum. No conversion between MTP and LTP is observed at $300 \mathrm{~K}$. After annealing to $350 \mathrm{~K}$, the LTP vibration intensities are reduced but still detectable in the spectrum in Fig. 8(e) suggesting depletion of the LTP and its conversion to the MTP (HTP). This conversion is driven by the thermal excitation and either occurs at the same surface site or is mediated by surface diffusion to an appropriate site. Annealing to $440 \mathrm{~K}$, Fig. 8(f), leaves only the HTP on the surface which is also characterized by the distinct $\beta_{3}$ high-temperature desorption peak as marked by the dotted line in Fig. 2(b). HREEL spectra upon benzene adsorption at $100 \mathrm{~K}$ on clean and on partially $\mathrm{H}$-passivated Si(100) surfaces for coverages $\theta_{\mathrm{C}_{6} \mathrm{H}_{6}}>1 \mathrm{ML}$ are shown in Figs. 8(g) and 8(h), respectively. In these two cases chemisorption leads mainly to the LTP with its characteristic losses at $537,1043,1616$, and $2950.5 \mathrm{~cm}^{-1}$. Additionally a physisorbed phase with unperturbed out-of-plane $\mathrm{C}-\mathrm{H}$ bending mode is detectable in Figs. 8(g) and 8(h). The latter implies that benzene saturation of the bare $\mathrm{Si}(100)$ and of a $0.4 \mathrm{ML}$ monohydride precovered $\mathrm{Si}(100)$ suppresses the MTP (HTP) formation at $100 \mathrm{~K}$. The same observations with respect to the temperature dependence of the vibrational spectra are valid for $\mathrm{C}_{6} \mathrm{H}_{6}$ adsorption on the nominally flat surface as shown in Fig. 9. The spectrum in Fig. 9(e) corresponds to benzene adsorption at $90 \mathrm{~K}$ and a coverage of $\theta_{\mathrm{C}_{6} \mathrm{H}_{6}}>1 \mathrm{ML}$. It reveals mainly physisorbed species with losses unperturbed relative to benzene physisorption on an entirely passivated surface shown in Fig. 9(f). The weak losses at 615 and $780 \mathrm{~cm}^{-1}$ are not sufficient to deduce which chemisorbed phase is present on the surface. However, the missing loss at $2904 \mathrm{~cm}^{-1}$ indicates that this is the LTP in analogy to the results on vicinal surfaces. In contrast, the latter mode is present in the spectrum for low coverages $\left(\theta_{\mathrm{C}_{6} \mathrm{H}_{6}}=0.3 \mathrm{ML}\right)$ in Fig. 9(a) adsorbed at $90 \mathrm{~K}$. Together with the observation of losses at 597 and $786 \mathrm{~cm}^{-1}$, this indicates the MTP (HTP). The absence of the LTP for low benzene coverages which have been adsorbed at $90 \mathrm{~K}$ is confirmed by the missing structures at 539, 1043, and $1287 \mathrm{~cm}^{-1}$. The latter LTP losses appear in Fig. 9(b) only after annealing to $200 \mathrm{~K}$ together with the disappearance of the loss at $705 \mathrm{~cm}^{-1}$ of the physisorbed phase. Annealing to $380 \mathrm{~K}$ entirely converts the LTP into a MTP (HTP) as is evident in Fig. 9(d).

HREEL spectra of $\mathrm{C}_{6} \mathrm{D}_{6}$ on a vicinal $\mathrm{Si}(100)$ surface are displayed in Fig. 10 after various thermal treatments. The spectrum in Fig. 10(a) has been taken after adsorption of 


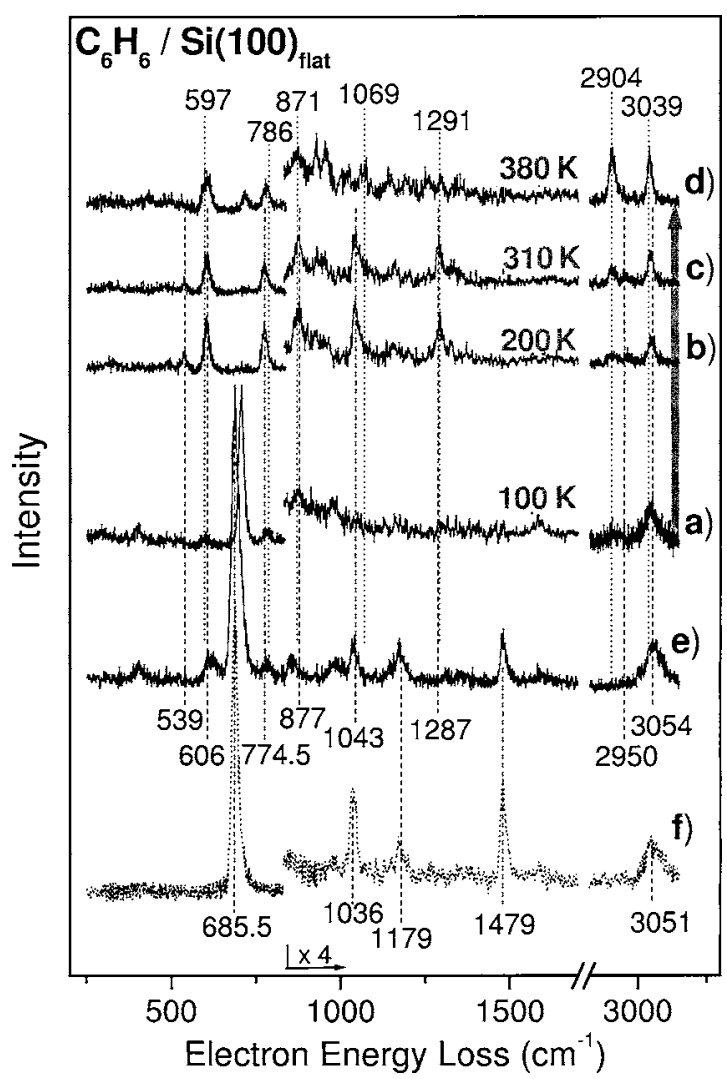

FIG. 9. HREEL spectra of $\mathrm{C}_{6} \mathrm{H}_{6}$ adsorbed on a nominally flat $\mathrm{Si}(100)$ surface as a function of annealing temperature $(4 \mathrm{eV}$ electron energy, measured at $90 \mathrm{~K}$ ): Low coverage spectra of $\theta=0.3$ taken (a) without annealing and after successive annealing (5 hold time) up to (b) $200 \mathrm{~K}$, (c) $310 \mathrm{~K}$, and (d) $380 \mathrm{~K}$. (e) Spectrum for saturation coverage at $90 \mathrm{~K}$. (f) Difference of the spectra measured on $\mathrm{H} / \mathrm{Si}(100)-(3 \times 1)$ with and without physisorbed benzene.

$\theta_{\mathrm{C}_{6} \mathrm{D}_{6}}=0.3 \mathrm{ML}$ at $40 \mathrm{~K}$. It does not show evidences for the existence of a chemisorbed phase because the structure around $670 \mathrm{~cm}^{-1}$ is $20 \mathrm{~cm}^{-1}$ blueshifted from the characteristic one for all chemisorbed phases at $650 \mathrm{~cm}^{-1}$. The only hint could be the double structure around $1570 \mathrm{~cm}^{-1}$ but it could alternatively belong to the physisorbed species. We cannot exclude the latter because in this frequency region [missing part of the curve in Fig. 10(h)] we have overlapped with the strong monodeuteride stretching mode. The spectrum in Fig. 10(b) upon annealing to $100 \mathrm{~K}$ again shows the chemisorbed phase with modes at 780, 1134, 1598, and $2165 \mathrm{~cm}^{-1}$ characteristic for the MTP (HTP). After annealing to $300 \mathrm{~K}$ [see Fig. 10(c)] the LTP appears additively on the surface with its vibration at $860 \mathrm{~cm}^{-1}$, which is reduced in intensity after annealing to $350 \mathrm{~K}$ (d) and vanishes after annealing to $440 \mathrm{~K}$ (e), thus indicating a phase transition at temperatures well above $300 \mathrm{~K}$. The spectrum in Fig. 10(f) of $\theta_{\mathrm{C}_{6} \mathrm{D}_{6}}>1$ adsorbed at $100 \mathrm{~K}$ indicates coexistence of chemisorbed benzene in the LTP and in the MTP (HTP). This result differs from the analogous $\mathrm{C}_{6} \mathrm{H}_{6}$ case but could be a result of the experimentally chosen two to three times slower dosing in the case of $\mathrm{C}_{6} \mathrm{D}_{6}$ adsorption. The spectrum for coverages $\theta_{\mathrm{C}_{6} \mathrm{D}_{6}}>1$ adsorbed at $100 \mathrm{~K}$ on a $0.4 \mathrm{ML}$ hydrogen-covered surface in Fig. $10(\mathrm{~g})$ shows only the presence of the LTP as a chemisorbed phase, in agreement with the results for hydrogenated benzene.

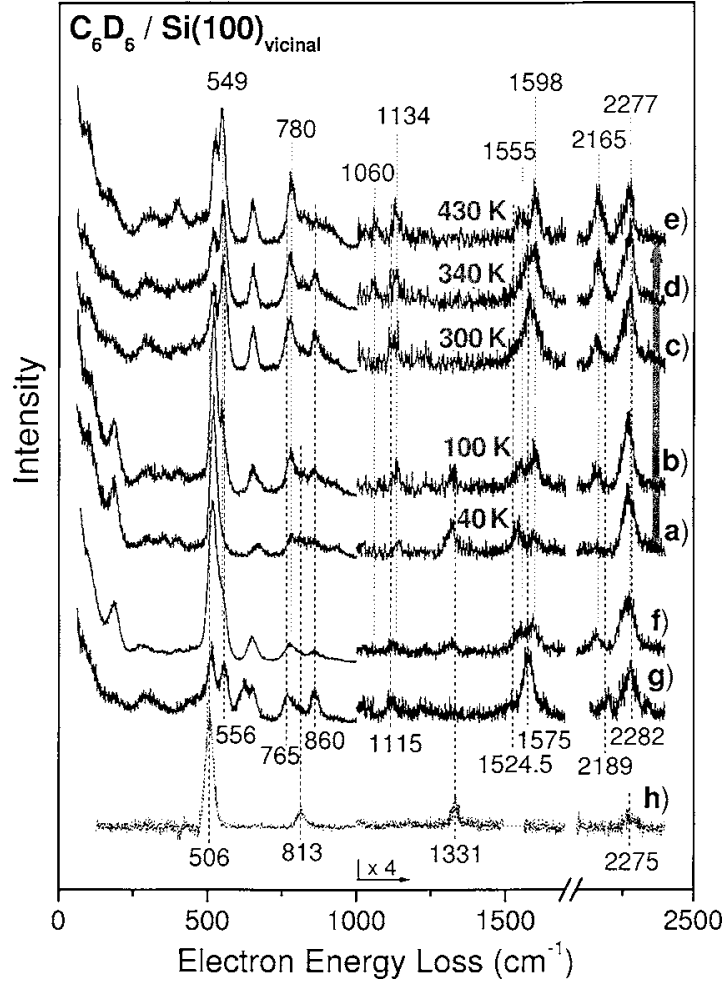

FIG. 10. HREEL spectra of $\mathrm{C}_{6} \mathrm{D}_{6}$ adsorbed on a vicinal $\mathrm{Si}(100)$ surface as a function of annealing temperature $(4 \mathrm{eV}$ electron energy, measured at $100 \mathrm{~K}$ ): Low coverage spectra of $\theta=0.3$ adsorbed at $40 \mathrm{~K}$, taken directly (a) after dosing and after successive annealing ( $5 \mathrm{~s}$ hold time) up to (b) $100 \mathrm{~K}$, (c) $300 \mathrm{~K}$, (d) $350 \mathrm{~K}$, and (e) $440 \mathrm{~K}$. (f) Spectrum for saturation coverage at $100 \mathrm{~K}$. (g) Spectrum for saturation at $100 \mathrm{~K}$ after passivation with $0.40 \mathrm{ML}$ atomic hydrogen at $650 \mathrm{~K}$. (i) Difference of the spectra measured on $\mathrm{D} / \mathrm{Si}(100)-(2 \times 1)$ surface with and without physisorbed benzene.

\section{DISCUSSION}

By using preadsorbed atomic hydrogen and annealing of different benzene coverages, we were able to separately prepare and vibrationally characterize three chemisorbed benzene phases on vicinal and nominally flat $\mathrm{Si}(100)$ surfaces. In total, 22 (22), 15 (21), and 14 (13) $\mathrm{C}_{6} \mathrm{H}_{6}$-derived vibrational modes $\left(\mathrm{C}_{6} \mathrm{D}_{6}\right.$-derived in brackets) for the three phases, LTP, MTP and HTP, respectively, have been experimentally resolved on vicinal and nominally flat $\mathrm{Si}(100)$ surfaces. All vibrational frequencies are summarized in Table I. Additionally the theoretically predicted vibrational modes for the standard butterfly configuration (SB in Fig. 1) reported by Staufer et al. ${ }^{9}$ as well as by Preuss and Bechstedt ${ }^{15}$ are presented there. Among the three phases, the LTP shows the best correspondence to the calculated vibrational modes for the standard butterfly geometry with an average discrepancy of $21 \mathrm{~cm}^{-1}\left(16 \mathrm{~cm}^{-1}\right)$ between the measured and calculated $\mathrm{C}_{6} \mathrm{H}_{6}\left(\mathrm{C}_{6} \mathrm{D}_{6}\right)$ frequencies above $500 \mathrm{~cm}^{-1}$. The observed small frequency differences between the LTP experimental values on vicinal and flat $\mathrm{Si}(100)$ surfaces are due to the different scattering geometries for which the cross sections of the modes are altered and thus a variation of the loss positions induced by adjacent peaks in the spectrum takes place. The appearance of new losses, e.g., the modes at 522, 707, 932, and $1085 \mathrm{~cm}^{-1}$, is also a result of the different measurement geometries with their specific scattering selec- 
TABLE I. Vibrational mode assignment of the different benzene phases on $5^{\circ}$ vicinal and nominally flat $\operatorname{Si}(100)$. The different phases LTP $\left(\beta_{1}\right)$, MTP $\left(\beta_{2}\right)$, and HTP $\left(\beta_{3}\right)$ are indicated at the top row. The calculated vibrational frequencies are taken from Refs. 9 and 15. In-phase and out-of-phase modes are abbreviated by (ip) and (op).

\begin{tabular}{|c|c|c|c|c|c|c|c|c|c|c|c|c|c|c|c|}
\hline \multirow[b]{2}{*}{ Symmetry } & \multirow{2}{*}{$\begin{array}{c}\text { Mode } \\
\text { description }\end{array}$} & \multirow{2}{*}{$\begin{array}{c}\text { Calc. } \\
\mathrm{C}_{6} \mathrm{H}_{6} \\
\text { (Ref. 9) }\end{array}$} & \multirow{2}{*}{$\begin{array}{c}\text { Calc. } \\
\mathrm{C}_{6} \mathrm{H}_{6} \\
\text { (Ref. 15) }\end{array}$} & \multicolumn{2}{|c|}{$\beta_{1} \mathrm{C}_{6} \mathrm{H}_{6}$} & \multicolumn{2}{|c|}{$\beta_{2} \mathrm{C}_{6} \mathrm{H}_{6}$} & \multicolumn{2}{|c|}{$\beta_{3} \mathrm{C}_{6} \mathrm{H}_{6}$} & \multirow{2}{*}{$\begin{array}{c}\text { Calc. } \\
\mathrm{C}_{6} \mathrm{D}_{6} \\
\text { (Ref. 9) }\end{array}$} & \multicolumn{2}{|c|}{$\beta_{1} \mathrm{C}_{6} \mathrm{D}_{6}$} & \multicolumn{2}{|c|}{$\beta_{2} \mathrm{C}_{6} \mathrm{D}_{6}$} & \multirow{2}{*}{$\begin{array}{l}\beta_{3} \mathrm{C}_{6} \mathrm{D}_{\boldsymbol{1}} \\
\text { Vicinal }\end{array}$} \\
\hline & & & & Vicinal & Flat & Vicinal & Flat & Vicinal & Flat & & Vicinal & Flat & Vicinal & Flat & \\
\hline$B 2$ & $\begin{array}{l}\mathrm{Si}-\mathrm{C}_{d} R_{x} \text { around the dimer } \\
+\mathrm{C}_{6} \mathrm{H}_{6} R_{z} \text { (op) }\end{array}$ & 194 & & 228 & & & & & & 179 & & & & & \\
\hline$A 1$ & $\begin{array}{l}\text { Butterfly bending } \\
+\mathrm{C}_{6} \mathrm{H}_{6}-\mathrm{Si}_{2} T_{z}\left(\mathrm{C}_{d} \text { ip }\right)\end{array}$ & 318 & 295 & 311 & & & & & & 285 & 290 & & & & \\
\hline$B 1$ & Asym. $\mathrm{Si}-C_{d}$ stretch & 467 & & 488 & 490 & & & & & 438 & 450 & 451 & & & \\
\hline$A 2$ & $\begin{array}{l}\mathrm{C}=\mathrm{C} \text { bonds } R_{z} \\
\text { around their centers }\end{array}$ & 474 & & & 522 & & & & & 431 & 483 & 500 & & 481 & \\
\hline$A 1$ & $\begin{array}{l}\text { Butterfly bending } \\
+\mathrm{Si}-\mathrm{C}_{4} \text { stretch }\left(\mathrm{C}_{d} \text { ip }\right)\end{array}$ & 523 & 514 & 537 & 539 & & & & & 486 & 512.5 & 520 & 521.5 & 525 & 521.5 \\
\hline$A 1$ & $<\left(\mathrm{C}, \mathrm{C}_{d}, \mathrm{C}\right)$ bending & 577 & 565 & 605 & 606 & 597 & 597 & 596 & 596 & 542 & 556 & 558 & 549 & 551 & 548 \\
\hline$B 1$ & $\begin{array}{l}\text { Asym. } \mathrm{C} \text { and } \mathrm{C}_{d} T_{z} \\
\left(\mathrm{C} \text { and } \mathrm{C}_{d} \text { op }\right)\end{array}$ & 666 & & & & & & & & 589 & & & & 621 & \\
\hline$B 2$ & $\begin{array}{l}\text { Out-of-pl. } \\
\text { C-H bending }\end{array}$ & 678 & & & 707 & 721 & 717 & 721 & 719 & 541 & & & & 582 & \\
\hline$A 1$ & $\begin{array}{l}\text { Collective out-of-pl. C-H } \\
\text { and } \mathrm{C}_{d}-\mathrm{H}_{d} \text { bendings (ip) }\end{array}$ & 755 & 757 & 774.5 & 774.5 & 784 & 786 & 784 & 786 & 634 & 651.5 & 652 & 649 & 648 & 650 \\
\hline$A 1$ & $\begin{array}{l}\text { Benzene } \\
\text { breathing }\end{array}$ & 870 & 899 & 876 & 877 & 868 & 871 & 864 & & 835 & 860 & 858 & 867 & & \\
\hline$B 1$ & $\mathrm{C}-\mathrm{C}_{d}$ stretch $+\mathrm{C}-\mathrm{H}$ bending & 871 & & & & & & & & 689 & & & & 711 & \\
\hline$B 1$ & $\begin{array}{l}\text { Out-of-pl. } \mathrm{C}-\mathrm{H} \text {, and } \mathrm{C}_{d}-\mathrm{H}_{d} \\
\text { bendings (ip) }\end{array}$ & 887 & & & 932 & 927 & 926 & & & 740 & & & & 759 & \\
\hline$B 1$ & $\begin{array}{l}\text { Out-of-pl. C-H, and } \mathrm{C}_{d}-\mathrm{H}_{d} \\
\text { bendings (op) }\end{array}$ & 929 & & 952 & & & & & & 917 & & 934 & & & \\
\hline$B 2$ & $\begin{array}{l}\mathrm{C}-\mathrm{C}_{d} \text { stretch } \\
+\mathrm{C}-\mathrm{H} \text { and } \mathrm{C}_{d}-\mathrm{H}_{d} \text { bendings }\end{array}$ & 945 & & & & 957 & 957 & 950 & & 768 & & & & & \\
\hline$A 1$ & $\begin{array}{l}\text { Isolated out-of-pl. } \\
\mathrm{C}_{d}-\mathrm{H}_{d} \text { bending }\end{array}$ & 1016 & 1010 & 1043.5 & 1043 & 1069 & 1069 & 1068 & 1068 & 747 & 765 & 762 & 780 & 795 & 779.5 \\
\hline$B 1$ & Out-of-pl. $\mathrm{C}_{d}-\mathrm{H}_{d}$ bending & 1065 & & & 1085 & & & & & 834 & & 890 & & & \\
\hline$B 2$ & $\begin{array}{l}\text { In-pl. } \mathrm{C}-\mathrm{H} \text { and } \mathrm{C}_{d}-\mathrm{H}_{d} \text { bendings } \\
\text { (op) }\end{array}$ & 1109 & 1103 & 1130 & & 1151 & 1142 & 1155 & 1159 & 788 & & 814.5 & 825 & 829 & 828 \\
\hline$A 1$ & In-pl. C-H & 1140 & 1140 & 1160 & 1157 & 1187 & 1187 & 1195 & & 835 & 860 & 858 & 912 & 920 & 913 \\
\hline$B 2$ & $\begin{array}{l}\text { In-pl. C-H and } \mathrm{C}_{d}-\mathrm{H}_{d} \\
\text { bendings (ip) }\end{array}$ & 1253 & & & & 1255 & 1252 & & & 1105 & & & 1060 & 1056 & 1061 \\
\hline$A 2$ & $\begin{array}{l}\text { In-pl. C-H and } \mathrm{C}_{d}-\mathrm{H}_{d} \\
\text { bendings (ip) }\end{array}$ & 1266 & & 1280 & 1287 & & & & & 985 & & 1012 & 1011 & 1013 & \\
\hline$A 2$ & $\begin{array}{l}\text { In-pl. C-H and } \mathrm{C}_{d}-\mathrm{H}_{d} \\
\text { bendings (op) }\end{array}$ & 1309 & & 1328 & 1330 & 1293 & 1291 & 1291 & 1290 & 1207 & 1217 & 1216 & & 1197 & \\
\hline$B 1$ & In-pl. C-H bending & 1340 & & 1376 & & & & 1335 & & 1146 & 1115 & 1114 & 1134 & & 1131 \\
\hline$B 2$ & Asym. $\mathrm{C}=\mathrm{C}$ stretch & 1570 & 1576 & 1567 & & 1590 & 1597 & 1589 & 1588 & 1528 & 1524.5 & 1526 & 1555 & 1558 & 1548 \\
\hline$A 1$ & Sym. $\mathrm{C}=\mathrm{C}$ stretch & 1623 & 1629 & 1616 & & 1635.5 & 1635 & 1636 & 1633 & 1583 & 1575 & 1579 & 1598 & 1596 & 1598 \\
\hline$A 1$ & $\mathrm{C}_{d}-\mathrm{H}_{4}$ stretch & 2978 & & 2950.5 & 2950 & 2904 & 2904 & 2904 & 2908 & 2193 & 2189 & 2198 & 2165 & 2165 & 2162.5 \\
\hline$B 1$ & $\mathrm{C}-\mathrm{H}$ stretch & 3065 & & & & & & & & 2258 & 2250 & 2260 & 2246 & 2244 & 2242 \\
\hline$A 1$ & $\mathrm{C}-\mathrm{H}$ stretch & 3081 & 3107 & 3050 & 3054 & 3037 & 3038.5 & 3034 & 3039 & 2291 & 2282 & 2285 & 2277 & 2279 & 2274 \\
\hline
\end{tabular}

tion rules. All ten totally symmetric $\left(A_{1}\right)$ modes above $200 \mathrm{~cm}^{-1}$ have been identified in the HREEL spectra for the LTP. Three of them (see Fig. 7) show significant dynamical dipole moments. The agreement between the symmetric and asymmetric $\mathrm{C}=\mathrm{C}$ stretching frequencies is remarkable, especially for the splitting of the $\mathrm{C}=\mathrm{C}$ stretching modes. It is calculated to $53(55) \mathrm{cm}^{-1}$ by Staufer et al. ${ }^{9}$ and to $53 \mathrm{~cm}^{-1}$ by Preuss and Bechstedt ${ }^{15}$ which can be compared with the experimental splitting of $49(50) \mathrm{cm}^{-1}$. Based on its vibrational characteristics in comparison with the theoretical results, ${ }^{9,15}$ we assign therefore the LTP as the benzene standard butterfly complex (SB in Fig. 1) which is di- $\sigma$ bonded to a single $\mathrm{Si}-\mathrm{Si}$ dimer.

The $\mathrm{C}=\mathrm{C}$ stretching doublet is an important fingerprint for all phases since it is well separated from all other vibra- tional modes and is a direct evidence for the presence of more than one carbon-carbon double bond in the adsorbed molecule. Among the stable benzene complexes on $\mathrm{Si}(100)$ shown in Fig. 1, only the butterfly (SB, 1,4-cyclohexadienelike) and the tilted (T, 1,3-cyclohexadiene-like) molecules have more than one carbon-carbon double bond, namely, two $\mathrm{C}=\mathrm{C}$ bonds. The tilted configuration with its molecular plane nonparallel to the surface has been ruled out previously by ARUPS (Ref. 6) and STM (Refs. 20 and 21) investigations. Additionally, the splitting of the $\mathrm{C}=\mathrm{C}$ stretching modes of 1,3-cyclohexadiene in the gas phase of $100 \mathrm{~cm}^{-1}$ (Ref. 42) is significantly larger than the splitting of $40 \mathrm{~cm}^{-1}$ found experimentally for all three phases. Therefore the presence of the $\mathrm{C}=\mathrm{C}$ stretching doublet together with the strength of the doublet splitting strongly suggests in all 
phases the butterflylike adsorption complex which corresponds to an electronically 1,4-cyclohexadiene-like molecular bonding configuration. This indicates that the tight bridge structure which is in some DFT calculations energetically preferred. ${ }^{10,12,14}$ is not realized under the given experimental conditions. On the other hand, a butterfly ground state and the absence of conversion to a tight bridge structure is in agreement with multireference cluster calculations by Jung and Gordon. ${ }^{13}$ Compared to the LTP, the symmetric and asymmetric $\mathrm{C}=\mathrm{C}$ stretching modes are blueshifted by $18(21) \mathrm{cm}^{-1}$ and $25(30) \mathrm{cm}^{-1}$ for $\mathrm{C}_{6} \mathrm{H}_{6}\left(\mathrm{C}_{6} \mathrm{D}_{6}\right)$ in the MTP and the HTP, respectively. For $\mathrm{C}_{6} \mathrm{H}_{6}$ in the MTP, the carbonhydrogen stretching frequency region contains again two well-defined bands which correspond to the $\mathrm{C}_{d}-\mathrm{H}_{d}$ and the $\mathrm{C}-\mathrm{H}$ stretching at the two $s p^{3}$ - and the four $s p^{2}$-hybridized carbon atoms. Both bands are redshifted with respect to the LTP by 46 and $15 \mathrm{~cm}^{-1}$ for the $\mathrm{C}_{d}-\mathrm{H}_{d}$ and the $\mathrm{C}-\mathrm{H}$ stretching modes, respectively. The direction of these shifts is toward the corresponding gaseous 1,4-cyclohexadiene values at $2825-2903$ and $3035 \mathrm{~cm}^{-1}$. ${ }^{42}$ In the case of deuterated benzene the three bands in the LTP are also preserved and are redshifted by 28,10 , and $5 \mathrm{~cm}^{-1}$ for the $\mathrm{C}_{d}-\mathrm{D}_{d}$ and the other two C-D stretching vibrations. Most of the LTP strong losses below $1500 \mathrm{~cm}^{-1}$ have their shifted analogs in the HREEL spectra of the MTP and the HTP. Additionally the dominant excitation mechanism, dipole versus impact scattering, is conserved for all modes. These observations suggest rather similar structures of the adsorbate complex in the three different phases independent of the surface vicinality. In view of the wide similarities, the following question arises: What causes the variation of the vibrational properties and what are the corresponding structural differences between the phases? We propose as discussed below that the differences can be attributed (i) to azimuthal-orientation variations of the butterflylike molecule relative to the silicon dimer and (ii) to changes of the molecular distortion in the different adsorbate complexes.

Since a di- $\sigma$ bonded, 1,4-cyclohexadiene-like benzene molecule has local $C_{2 v}$ symmetry, the molecular orientation can be investigated by considering the impact selection rules for HREELS (see also Sec. III B). On the nominally flat surface which possesses two orthogonal $(2 \times 1)$ domains, the sample was oriented for HREELS measurements in such a way that the scattering plane was aligned along a lowsymmetry direction at an angle of $45^{\circ}$ with respect to the dimer rows [along the common direction for both $(2 \times 1)$ domains]. On the single-domain surfaces the scattering plane was aligned along the high-symmetry direction parallel to the $\mathrm{Si}-\mathrm{Si}$ dimer (orthogonal to the dimer rows). In the former case of measurement along a low-symmetry direction, all modes are allowed with respect to impact scattering. However, in the latter case, selection rules state that modes which are antisymmetric with respect to the scattering plane cannot be excited by impact scattering. Vibrations with $A_{2}$ and $B_{2}$ symmetries are odd with respect to the scattering plane and thus are impact forbidden, while those with $A_{1}$ and $B_{1}$ symmetries are even and allowed. Because the local $C_{2 v}$ symmetry is not strictly fulfilled for the vicinal $\mathrm{Si}(100)$ surface due to the geometry of the double-atomic steps and because of small sample areas with a minority $(1 \times 2)$ reconstruction due to a nonperfect single-domain surface as discussed previously, ${ }^{6,43}$ some forbidden modes can be observed in the spectra but with strongly reduced intensities. Applying the impact selection rules to the pair of the symmetric $\left(A_{1}\right)$ and the antisymmetric $\left(B_{2}\right) \mathrm{C}=\mathrm{C}$ stretching vibrations, the intensity ratio of 5:1 for the LTP is characteristic for an adsorption geometry with the $\mathrm{C}=\mathrm{C}$ double bonds parallel to the $\mathrm{Si}-\mathrm{Si}$ dimer (parallel to the scattering plane). The intensity ratio of $2: 1$ (3:1) for the MTP (HTP) shows that the benzene molecule in the MTP (HTP) is no longer parallel to the scattering plane and consequently the antisymmetric mode becomes more intense (not impact forbidden). The intensity ratios show a difference also between the MTP and HTP.

Up to now we have considered these two phases separately but the MTP consists of species which appear as $\beta_{2}$ and $\beta_{3}$ peaks in the TPD spectra. The $\beta_{2}+\beta_{3}$ (MTP) and $\beta_{3}$ (HTP) structures show essentially the same vibrational characteristics independent of the relative population. This is in contrast to their different desorption energies. Differences between their HREEL spectra are only small frequency shifts close to the experimental resolution. Significant variations occur only in the relative loss intensities indicating variations of the molecular orientation.

The HREELS investigations at low benzene coverages as a function of annealing temperature reveal the presence of a chemisorbed phase upon adsorption at $100 \mathrm{~K}$. This phase has the vibrational characteristics of the MTP (HTP) and coexists with a physisorbed phase which has slightly shifted frequencies relative to benzene multilayers. The physisorbed phase is converted to the LTP after annealing to $200 \mathrm{~K}$ while the MTP (HTP) remains intact. Annealing to temperatures above $350 \mathrm{~K}$ leads to a reduction of the LTP and an increase of the MTP (HTP) population. These results suggest a sitespecific chemisorption and probably thermally induced adsorbate diffusion on the surface. Benzene saturation at $100 \mathrm{~K}$ or adsorption on a partially hydrogen-passivated surface suppresses the MTP (HTP) formation at $100 \mathrm{~K}$ and favors the LTP chemisorption. The hydrogen blocking of the MTP and the HTP in the entire temperature interval between $100 \mathrm{~K}$ and the desorption temperature contains important information for the site-specific chemisorption on the $\mathrm{Si}(100)$ surface. On $\mathrm{Si}(100)$ atomic hydrogen adsorption at $650 \mathrm{~K}$ forms monohydride pairs on a single $\mathrm{Si}-\mathrm{Si}$ dimer. ${ }^{39,44}$ At this temperature diffusion of the hydrogen pairs takes place ${ }^{45}$ and leads to clustering. ${ }^{39,46}$ Step and defect sites are hydrogen passivated $^{47}$ and the strain induced by these surface inhomogeneities is reduced. ${ }^{48}$ Therefore, the MTP (HTP) seems to be related to adsorption on dimers which are strained by defects or steps. This observation is supported by the TPD spectrum of benzene adsorbed on a nominally flat surface passivated by atomic hydrogen at $400 \mathrm{~K}$ as presented in Fig. 11(c). In this spectrum a $\beta_{3}{ }^{\prime}$ peak with HTP vibrational character is present and shifted to higher temperatures relative to the $\beta_{3}$ of benzene adsorbed on a clean surface. The $\beta_{2}$ is missing and the $\beta_{1}{ }^{\prime}$ is slightly shifted to lower temperatures relative to $\beta_{1}$. We suppose that the dihydride formed at $400 \mathrm{~K}$ acts as a missing-dimer-like point defect on the surface and in this way produces the necessary strain for the 


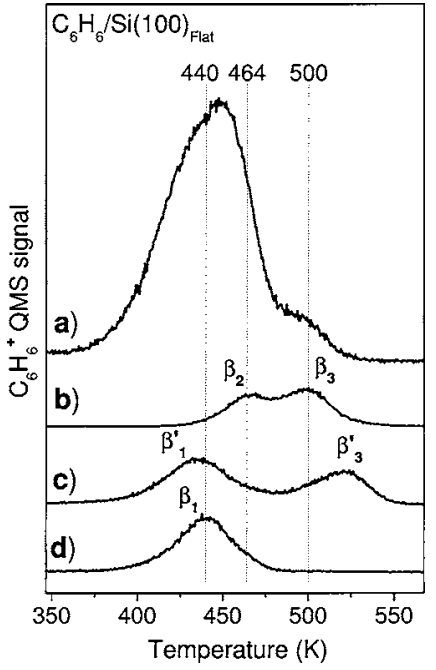

FIG. 11. TPD spectra of $\mathrm{C}_{6} \mathrm{H}_{6}$ chemisorbed on a nominally flat $\mathrm{Si}(100)$ surface. (a) Benzene saturation at $90 \mathrm{~K}$. (b) Saturated layer annealed up to $440 \mathrm{~K}$. (c) Benzene saturation after passivation with $0.25 \mathrm{ML}$ atomic hydrogen at $400 \mathrm{~K}$. (d) Benzene saturation after passivation with $0.25 \mathrm{ML}$ atomic hydrogen at $650 \mathrm{~K}$.

HTP formation. Hence, the HTP can be assigned to adsorption on silicon dimers near surface defects (point defects, steps). The $\beta_{2}$ phase appears as not defect induced, but it rather depends on the free terrace area which is reduced after hydrogen adsorption. The HREELS results suggest that the benzene molecules in the MTP (HTP) are rotated (most likely by $90^{\circ}$ ) relative to those in the LTP which means that their $\mathrm{C}=\mathrm{C}$ axes are not parallel to the $\mathrm{Si}-\mathrm{Si}$ dimer bond. As all phases exhibit 1,4-cyclohexadiene-like vibrational spectra we propose for the MTP and the HTP a benzene butterfly bridge structure which is di- $\sigma$ bonded to two Si atoms of two different $\mathrm{Si}-\mathrm{Si}$ dimers which are adjacent in a dimer row. These butterfly bridge geometries are either defect assisted (HTP) or require surface areas free of defects and adsorbates in the low coverage regime $\left(\beta_{2}\right.$-MTP). The site-specific nature of the adsorption geometry is strongly supported by the MTP (HTP) formation already at low temperature $(100 \mathrm{~K})$ at low coverages. In the butterfly bridge geometry as proposed for the MTP and the HTP, the benzene ring distortion will be opposite to those of the standard butterfly geometry (LTP) which can explain the $\mathrm{C}=\mathrm{C}, \mathrm{C}-\mathrm{H}$, and $\mathrm{C}_{d}-\mathrm{H}_{d}$ stretching mode shifts. The $\mathrm{C}=\mathrm{C}$ and the $s p^{2} \mathrm{C}-\mathrm{H}$ stretching modes undergo a redshift from 1636 to $1616 \mathrm{~cm}^{-1}$ and a blueshift from 3038 to $3050 \mathrm{~cm}^{-1}$, respectively. These differential shifts between the LTP and the MTP (HTP) have the same trends as between 1,4-cyclohexadiene and 1,5-cyclooctadiene $^{42}$ where the carbon ring and, in particular, the $\mathrm{C}=\mathrm{C}$ undergo similar distortion changes. Potential candidates for the MTP and the HTP are the tilted bridge butterfly (TB) and the diagonal bridge butterfly (DB) benzene complexes as depicted in Fig. 1. Note that these structures have been derived as stable configurations by Silvestrelli et al. ${ }^{10}$ based on a DFT study. The calculated binding energies for adsorption on $\mathrm{Si}(100)-(2 \times 1)$ are $2.06 \mathrm{eV}(\mathrm{SB}), 2.08 \mathrm{eV}$ (TB), and $1.70 \mathrm{eV}(\mathrm{DB})$, while for the $c(4 \times 2)$ surface reconstruction binding energies of $2.20 \mathrm{eV}(\mathrm{SB}), 1.99 \mathrm{eV}$ (TB), and $2.24 \mathrm{eV}$ (DB) have been calculated. ${ }^{10}$ Apparently the relative binding energies are sensitive to the surface strain, in agreement with our proposal. At the experimentally used adsorption temperatures well below $200 \mathrm{~K}$, the $\mathrm{Si}(100)$ surface is covered with large $c(4 \times 2)$-reconstructed areas as confirmed by LEED observations. The $c(4 \times 2)$ reconstruction should slightly favor the DB structure among the three butterfly configurations according to the calculations of Silvestrelli et al. ${ }^{10}$ Based on this calculation benzene adsorption in the MTP with its characteristic $\beta_{2}$ desorption peak might correspond to the DB configuration. However, the HREELS data alone cannot differentiate between both bridge structures, TB and DB, without further theoretical support. Potentially the three identified benzene phases might present alternative explanations for the recent coverage dependent photoemission data by Kim et $a .^{29}$ and some STM observations. ${ }^{12,21}$ Since the present work relies on spectroscopic evidence, further detailed experimental studies, e.g., by STM, for the different benzene phases on flat and vicinal $\mathrm{Si}(100)$ can add complementary evidence for this important organic-semiconductor adsorption system.

\section{SUMMARY AND CONCLUSIONS}

Based on highly resolved vibrational spectra and various adsorption, annealing, and site blocking treatments, three different chemisorbed benzene $\left(\mathrm{C}_{6} \mathrm{H}_{6}\right.$ and $\left.\mathrm{C}_{6} \mathrm{D}_{6}\right)$ phases on vicinal and nominally flat $\mathrm{Si}(100)$ surfaces have been separated and identified. These phases have distinct thermal desorption characteristics and show different vibrational spectra. However, the spectra for the combination of different phases agree where applicable with previous studies of lower experimental resolution.

The chemisorbed benzene phase which appears as the lowest temperature structure in TPD spectra $\left(\beta_{1}\right.$ peak, LT phase) is assigned as a 1,4-cyclohexadiene-like benzene molecule di- $\sigma$ bonded to a single $\mathrm{Si}-\mathrm{Si}$ dimer on the flat as well as on the vicinal $\mathrm{Si}(100)$ surface. This assignment is based on the excellent agreement between the experimental vibrational frequencies for $\mathrm{C}_{6} \mathrm{H}_{6}$ and for $\mathrm{C}_{6} \mathrm{D}_{6}$ and previous density-functional cluster calculations. ${ }^{9,15}$ The good agreement is illustrated by the identification of all ten totally symmetric $\left(A_{1}\right)$ modes above $200 \mathrm{~cm}^{-1}$ and the matching of the predicted and experimentally observed symmetric to asymmetric $\mathrm{C}=\mathrm{C}$ stretching mode positions and splitting. For saturation coverage the LT phase is the dominant benzene species on flat and vicinal $\mathrm{Si}(100)$. By preadsorption of a small amount of atomic hydrogen for step and defect saturation, a pure preparation of this phase is possible which is also important for reference spectra.

The other two chemisorbed benzene phases (mediumand high-temperature phases) on $\mathrm{Si}(100)$ have not been separated or characterized in detail before. Based on their vibrational spectra they are identified also as 1,4-cyclohexadienelike benzene structures. Independent of the surface vicinality, the $\mathrm{C}=\mathrm{C}$ stretching doublets with their characteristic splitting can be observed. Based on the shift of this doublet and by application of electron scattering selection rules, we assign these medium- and high-temperature phases again as adsorbed benzene complexes which are in a butterfly bridge 
configuration di- $\sigma$ bonded to two $\mathrm{Si}$ atoms of two adjacent $\mathrm{Si}-\mathrm{Si}$ dimers in the dimer row. For the HT phase which appears as the highest temperature structure with a $\beta_{3}$ desorption peak at about $500 \mathrm{~K}$, we proposed a butterfly bridge configuration involving silicon dimers strained by surface inhomogeneities as defects or steps. On the $5^{\circ}$ vicinal surface, benzene in the HTP contributes about $20 \%$ to the benzene monolayer coverage.

The benzene middle-temperature phase with a desorption peak $\beta_{2}$ at about $460 \mathrm{~K}$ is formed for low coverages already after adsorption at $100 \mathrm{~K}$. Its appearance is more clearly visible on flat surfaces most likely due to larger $c$ (4 $\times 2$ )-reconstructed areas which are free of inhomogeneities. Based on this observation and the binding energies calculated from first principles in the work of Silvestrelli et al., ${ }^{10}$ we tentatively assign the MTP as a 1,4-cyclohexadiene-like molecule (DB) di- $\sigma$ bonded to diagonal silicon atoms on adjacent $\mathrm{Si}-\mathrm{Si}$ dimers in a dimer row.

\section{ACKNOWLEDGMENTS}

This work was supported by the Deutsche Forschungsgemeinschaft through SFB 338.

${ }^{1}$ J. T. Yates, Science 279, 335 (1998).

${ }^{2}$ M. A. Filler and S. F. Bent, Prog. Surf. Sci. 73, 1 (2003).

${ }^{3}$ A. S. Blum, J. G. Kushmerick, D. P. Long, C. H. Patterson, J. C. Yang, J. C. Henderson, Y. X. Yao, J. M. Tour, R. Shashidhar, and B. R. Ratna, Nat. Mater. 4, 167 (2005).

${ }^{4}$ B. I. Craig, Surf. Sci. Lett. 280, 279 (1993).

${ }^{5}$ H. D. Jeong, S. Ryu, Y. S. Lee, and S. Kim, Surf. Sci. Lett. 344, L1226 (1995).

${ }^{6}$ S. Gokhale, P. Trischberger, D. Menzel, W. Widdra, H. Dröge, H.-P. Steinrück, U. Birkenheuer, U. Gutdeutsch, and N. Rösch, J. Chem. Phys. 108, 5554 (1998).

${ }^{7}$ U. Birkenheuer, U. Gutdeutsch, and N. Rösch, Surf. Sci. 409, 213 (1998); S. Alavi, R. Rousseau, and T. Seideman, J. Chem. Phys. 113, 4412 (2000); X. Lu, M. C. Lin, X. Xu, N. Q. Wang, and Q. N. Zhang, Sci. China, Ser. B: Chem. 44, 473 (2001); J. R. Hahn, H. Jeong, and S. Jeong, J. Chem. Phys. 123, 244702 (2005); N. A. Besley and A. J. Blundy, J. Phys. Chem. B 110, 1701 (2006).

${ }^{8}$ R. A. Wolkow, G. P. Lopinski, and D. J. Moffatt, Surf. Sci. 416, L1107 (1998); W. A. Hofer, A. J. Fisher, G. P. Lopinski, and R. A. Wolkow, ibid. 482, 1181 (2001).

${ }^{9}$ M. Staufer, U. Birkenheuer, T. Belling, F. Nortemann, N. Rösch, W. Widdra, K. L. Kostov, T. Moritz, and D. Menzel, J. Chem. Phys. 112, 2498 (2000).

${ }^{10}$ P. L. Silvestrelli, F. Ancilotto, and F. Toigo, Phys. Rev. B 62, 1596 (2000).

${ }^{11}$ S. Alavi, R. Rousseau, S. N. Patitsas, G. P. Lopinski, R. A. Wolkow, and T. Seideman, Phys. Rev. Lett. 85, 5372 (2000).

${ }^{12}$ W. A. Hofer, A. J. Fisher, G. P. Lopinski, and R. A. Wolkow, Phys. Rev. B 63, 085314 (2001).

${ }^{13}$ Y. S. Jung and M. S. Gordon, J. Am. Chem. Soc. 127, 3131 (2005).
${ }^{14}$ J. Y. Lee and J. H. Cho, Phys. Rev. B 72, 235317 (2005).

${ }^{15}$ M. Preuss and F. Bechstedt, Phys. Rev. B 73, 155413 (2006).

${ }^{16}$ Y. Taguchi, M. Fujisawa, T. T. Akaoka, T. Okada, and M. Nishijima, J. Chem. Phys. 95, 6870 (1991).

${ }^{17}$ Q. Li and K. T. Leung, Surf. Sci. 479, 69 (2001).

${ }^{18}$ X. J. Zhou and K. T. Leung, J. Phys. Chem. B 110, 9601 (2006).

${ }^{19}$ K. W. Self, R. I. Pelzel, J. H. G. Owen, C. Yan, W. Widdra, and W. H. Weinberg, J. Vac. Sci. Technol. A 16, 1031 (1998).

${ }^{20}$ G. P. Lopinski, T. M. Fortier, D. J. Moffatt, and R. A. Wolkow, J. Vac. Sci. Technol. A 16, 1037 (1998).

${ }^{21}$ G. P. Lopinski, D. J. Moffatt, and R. A. Wolkow, Chem. Phys. Lett. 282, 305 (1998).

${ }^{22}$ B. Borovsky, M. Krueger, and E. Ganz, Phys. Rev. B 57, R4269 (1998).

${ }^{23}$ D. E. Brown, D. J. Moffatt, and R. A. Wolkow, Science 279, 542 (1998); R. J. Hamers, J. S. Hovis, C. M. Greenlief, and D. F. Padowitz, Jpn. J. Appl. Phys., Part 1 38, 3879 (1999); R. A. Wolkow, Annu. Rev. Phys. Chem. 50, 413 (1999).

${ }^{24}$ P. Kruse and R. A. Wolkow, Appl. Phys. Lett. 81, 4422 (2002).

${ }^{25}$ M. J. Kong, A. V. Teplyakov, J. G. Lyubovitsky, and S. F. Bent, Surf. Sci. 411, 286 (1998).

${ }^{26}$ Y. Taguchi, Y. Ohta, T. Katsumi, K. Ichikawa, and O. Aita, J. Electron Spectrosc. Relat. Phenom. 88-91, 671 (1998); N. Witkowski, F. Hennies, A. Pietzsch, S. Mattsson, A. Föhlisch, W. Wurth, M. Nagasono, and M. N. Piancastelli, Phys. Rev. B 68, 115408 (2003).

${ }^{27}$ A. Fink, W. Widdra, W. Wurth, C. Keller, M. Stichler, A. Achleitner, G. Comelli, S. Lizzit, A. Baraldi, and D. Menzel, Phys. Rev. B 64, 045308 (2001); M. Nagao, Y. Yamashita, S. Machida, K. Hamaguchi, F. Yasui, K. Mukai, and J. Yoshinobu, Surf. Sci. 513, 413 (2002).

${ }^{28}$ M. Shimomura, M. Munakata, K. Honma, S. M. Widstrand, L. Johansson, T. Abukawa, and S. Kono, Surf. Rev. Lett. 10, 499 (2003).

${ }^{29}$ Y. K. Kim, M. H. Lee, and H. W. Yeom, Phys. Rev. B 71, 115311 (2005).

${ }^{30}$ M. J. Kong, A. V. Teplyakov, J. Jagmohan, J. G. Lyubovitsky, C. Mui, and S. F. Bent, J. Phys. Chem. B 104, 3000 (2000); Y. C. Li, W. N. Wang, Y. Cao, and K. N. Fan, Acta Chimica Sinica 60, 653 (2002).

${ }^{31}$ N. Witkowski, O. Pluchery, and Y. Borensztein, Phys. Rev. B 72, 075354 (2005).

${ }^{32}$ U. Birkenheuer, U. Gutdeutsch, N. Rösch, A. Fink, S. Gokhale, D. Menzel, P. Trischberger, and W. Widdra, J. Chem. Phys. 108, 9868 (1998).

${ }^{33}$ A. Fink, D. Menzel, and W. Widdra, J. Phys. Chem. B 105, 3828 (2001).

${ }^{34}$ K. L. Kostov, M. Gsell, P. Jakob, T. Moritz, W. Widdra, and D. Menzel, Surf. Sci. 394, L138 (1997).

${ }^{35}$ P. Feulner and D. Menzel, J. Vac. Sci. Technol. 17, 662 (1980).

${ }^{36}$ T. Moritz, D. Menzel, and W. Widdra, Surf. Sci. 428, 64 (1999).

${ }^{37}$ S. Gokhale, A. Fink, P. Trischberger, K. Eberle, and W. Widdra, J. Vac. Sci. Technol. A 19, 706 (2001).

${ }^{38}$ Y. J. Chabal and K. Raghavachari, Phys. Rev. Lett. 53, 282 (1984).

${ }^{39}$ J. J. Boland, Phys. Rev. Lett. 65, 3325 (1990).

${ }^{40}$ U. Bischler and E. Bertel, J. Vac. Sci. Technol. A 11, 458 (1993).

${ }^{41}$ P. Jakob and D. Menzel, Surf. Sci. 220, 70 (1989).

${ }^{42}$ NIST Standard Reference Database, 2002 (http://webbook.nist.gov/ chemistry).

${ }^{43}$ A. Fink, R. Huber, and W. Widdra, J. Chem. Phys. 115, 2768 (2001).

${ }^{44}$ W. Widdra, S. I. Yi, R. Maboudian, G. A. D. Briggs, and W. H. Weinberg, Phys. Rev. Lett. 74, 2074 (1995).

${ }^{45}$ D. R. Bowler, M. Fearn, C. M. Goringe, A. P. Horsfield, and D. G. Pettifor, J. Phys.: Condens. Matter 10, 3719 (1998).

${ }^{46}$ J. J. Boland, Surf. Sci. 261, 17 (1992).

${ }^{47}$ M. B. Raschke and U. Höfer, Phys. Rev. B 59, 2783 (1999).

${ }^{48}$ E. Pehlke and P. Kratzer, Phys. Rev. B 59, 2790 (1999). 